\title{
The importance of pedagogical content knowledge in curriculum development for illumination engineering
}

Stephen Pompea, Constance Walker

Stephen M. Pompea, Constance E. Walker, "The importance of pedagogical content knowledge in curriculum development for illumination engineering," Proc. SPIE 10452, 14th Conference on Education and Training in Optics and Photonics: ETOP 2017, 104526R (16 August 2017); doi: 10.1117/12.2270022

EDEent: 14th Conference on Education and Training in Optics and Photonics, ETOP 2017, 2017, Hangzhou, China 


\title{
The importance of pedagogical content knowledge in curriculum development for illumination engineering
}

\author{
Stephen M. Pompea and Constance E. Walker \\ The National Optical Astronomy Observatory, 950 N. Cherry Avenue, Tucson AZ USA 85719
}

\begin{abstract}
An understanding of pedagogical content knowledge (PCK) and educative materials has been critical to our teaching programs in illumination engineering. We will discuss the PCK basis of a number of innovative curriculum efforts at the National Optical Astronomy and how we develop "educative materials" that improve educator content knowledge, pedagogical knowledge, and contextual knowledge. We also describe the process and team approach required to create these "educative materials." The foundation of our work at NOAO were two previous projects at the NASA Classroom of the Future. These projects created educative curricular materials with sophisticated science content integrated with a deep, authentic understanding of science process. Additional curricula with these attributes were developed at NOAO for the NSF-sponsored Hands-On Optics project (SPIE, OSA, and NOAO), for the citizen science project Globe at Night (NOAO), and for the Quality Lighting Teaching Kits (NOAO, International Astronomical Union, OSA Foundation, SPIE, CIE, and the International Dark Sky Association). These projects all strove to create educative instructional materials that can enhance the pedagogical content knowledge of educators.
\end{abstract}

Keywords: pedagogical content knowledge, illumination engineering, instructional materials development, educative curriculum materials

\section{INTRODUCTION}

This paper describes how Pedagogical Content Knowledge (PCK), the domain specific knowledge of subject matter and pedagogy that educators use daily, can be used in curriculum development for illumination engineering. We describe how high quality "educative curriculum materials" can help improve PCK in curricula and instructional materials. We also describe how these materials can be developed by highly skilled hybrid teams familiar with the subject matter and with the practice of science. These teams have built materials with an authentic approach that incorporates problembased learning, which has been shown to be highly successful in photonics education. ${ }^{1,2}$

We describe the development of several sets of instructional materials that have led to the present set of programs for illumination engineering and for optics and photonics education at the National Optical Astronomy Observatory. A summary of these programs created at NOAO was presented at a previous ETOP conference. ${ }^{3}$ This paper describes some progressive aspects of these programs and materials.

\section{WHAT IS PEDAGOGICAL CONTENT KNOWLEDGE?}

Pedagogical Content Knowledge (PCK) is an education term that describes several interconnected domains of knowledge that are useful to the science educator teaching in a school or in an out of school context. ${ }^{4}$ The most important domains are subject specific content knowledge and knowledge of the pedagogy used in teaching a subject. The broader contextual knowledge that frames the teaching may also be important. This pedagogical content knowledge can be complex, since it is only one aspect of an educator's professional knowledge, and may be tied to the specific educator, the specific topic, and even the specific teaching situation. ${ }^{5,6} \mathrm{PCK}$ may represent a repertoire of pedagogical approaches that the experienced educator develops after teaching a topic multiple times. ${ }^{7}$ These elements used together are important in the effective teaching of a broad subject such as illumination engineering.

14th Conference on Education and Training in Optics and Photonics: ETOP 2017, edited by Xu Liu,

Xi-Cheng Zhang, Proc. of SPIE Vol. 10452, 104526R · ( 2017 ICO, IEEE, OSA, SPIE

CCC code: $0277-786 X / 17 / \$ 18 \cdot$ doi: $10.1117 / 12.2270022$ 
To illustrate the components: content knowledge is what is usually taught directly in classes. It would be, for example, light being described as waves with a wavelength, the concept that light moves in a straight line, or the definition of measurement terms such as "lux." Pedagogical knowledge relates to how the educator would teach a subject. It might include an awareness of student misconceptions or the naïve theories that they bring to the subject when they are first learning about it. It might also be assessment of which concepts can be taught at which grade levels or to which students. The third area is contextual knowledge. The contextual knowledge domain consist of the broader knowledge such as knowledge of the scientific method and how it is relevant to the lesson. If content knowledge is "what is being taught", pedagogical knowledge is "how it is being taught". Contextual knowledge is the larger framework (e.g., the scientific method). Pedagogical content knowledge is the superset of these different domains.

Pedagogical content knowledge is viewed on a continuum, with educators acquiring more of it through appropriate training and experience. Educators acquire it before they begin teaching, during their pre-service training, and during the teaching careers. The key hope from an educational improvement perspective is that the gains in teacher pedagogical content knowledge will lead to learning gains in students. A teacher with better content knowledge who know to teach the subject to a specific audience should create student gains over a less prepared or less experienced teacher. A key point, however, is that it is very difficult to provide enough additional training to educators once they have begun teaching. The daily demands of the position make less time available for improving content knowledge or in learning additional pedagogically useful approaches. How then might the quality of teaching improve?

A complementary approach to improving science education in both the classroom and out of school settings is for educators to use instructional materials that help improve their PCK. This approach emphasizes the development and use of high quality instructional materials. Of course, additional professional development and training can be useful so one approach does not preclude the other. If educational materials contain well-tested approaches and model best practices from experienced and successful teachers, then perhaps the PCK of the teachers using these materials can be improved.

The instructional materials that can help create gains in the PCK of educators are called "educative curriculum materials". $8,9,10$ They can help educators improve their teaching by increasing their content knowledge and their pedagogical knowledge through the process of teaching with materials that reflect best practices in all aspects of PCK.

\section{THE ROLE OF "EDUCATIVE CURRICULUM MATERIALS"}

Educative curriculum materials are not only useful for the teacher but can be especially appealing to the student since they can be creative and science process-oriented rather than emphasizing memorization and repetition. These materials can have content that goes deeper and can appeal to most students, and especially to gifted students who are easily bored or turned off by repetition. For these students, there is a special appeal from materials that go deeper, use less repetition, and create a sense of ownership of the educational process. With these materials, there is a deeper exposure to the underlying pedagogy that reinforces an understanding of the process of science. The materials may even be remembered by students years later for their innovative approaches or interesting selection of topics.

One approach to developing these high-quality instructional materials is to have them designed and developed by teams that have experience in the different components of PCK. These teams can also combine these components in creative and powerful ways. There is a large advantage to using these materials. Teachers will not have to compensate for poor quality materials that have outdated or inaccurate content, or ineffective approaches. For example, high-quality educative materials in our programs that will be described later have many characteristics which align themselves with authentic science practices. An instructor who uses these educational materials will be having students do science in authentic ways rather than reading about inauthentic practices. They may be addressing science topics that are considered important for today and the future. Since many science teachers have not conducted scientific research or are not able to keep up with the hot topics in the field this distinction is quite important.

Note that these desirable properties can also be built into the training or preparation program for educators or can be acquired by educators as they gain experience. However, building them into nationally distributed instructional materials provides a large number of teachers a wide exposure to expert knowledge in these areas. As noted, the instructional materials can also provide a stronger sense of the culture and essence of doing science, which may not be present in the 
classroom subculture. ${ }^{11}$ For example, high-quality instructional materials encourage a questioning and experimental approach, which may be lacking in classrooms but is an integral part of the process of science.

Table 1: Properties of Educative Materials developed by teams that combine deep science and science education knowledge.

\begin{tabular}{|l|l|}
\hline $\begin{array}{l}\text { Increased and more accurate use of current science } \\
\text { vocabulary }\end{array}$ & $\begin{array}{l}\text { Misconceptions can be understood and dealt with } \\
\text { using best practices }\end{array}$ \\
\hline Increased depth and accuracy of science content & Better thought out assessments \\
\hline $\begin{array}{l}\text { Science concept descriptions can be written by } \\
\text { experts }\end{array}$ & More reliance on authentic assessment \\
\hline $\begin{array}{l}\text { Science concept knowledge can be sequentially } \\
\text { developed }\end{array}$ & Increased and more authentic use of science tools \\
\hline $\begin{array}{l}\text { No excessive reliance on the teacher as the source of } \\
\text { complex content knowledge }\end{array}$ & Greater use and more authentic use of science data \\
\hline More cutting edge problem solving and topics & $\begin{array}{l}\text { Can be based on new and more relevant research } \\
\text { techniques and research problems }\end{array}$ \\
\hline More nuanced approaches & Better modeling of engineering practices \\
\hline $\begin{array}{l}\text { Can be based on research on understanding of student } \\
\text { reasoning }\end{array}$ & $\begin{array}{l}\text { Longer-lasting materials can withstand the test of } \\
\text { time since they incorporate cutting edge topics }\end{array}$ \\
\hline
\end{tabular}

We believe that the use of educative materials to develop pedagogical content knowledge can lead to:

- A deeper understanding of the subject by students

- Less misunderstanding of key concepts

- Accessible approaches to specialized content

- More interesting and diverse approaches to the teaching

- A more integrated laboratory element

- Increased use of investigative vs. lecture-based approaches

- A deeper understanding of science and engineering practices

- Greater use of authentic assessment approaches

\section{EXAMPLES OF EDUCATIVE CURRICULUM MATERIALS}

Here are some examples of educative curriculum materials developed at NOAO or by a team that included an NOAO staff member before they worked NOAO. All of these materials have strong support for pedagogical content knowledge.

\section{A. Astronomy Village ${ }^{\circledR}$}

The multimedia educational programs Astronomy Village $e^{\circledR}$ : Investigating the Universe ${ }^{\mathrm{TM}}$ and the Astronomy Village ${ }^{\circledR}$ : Investigating the Solar System ${ }^{\mathrm{TM}}$ (funded respectively by NASA and the National Science Foundation) were exemplary products incorporating problem-based learning and a keen understanding of the process of conducting scientific investigations. ${ }^{12,13,14,15}$ Both programs were developed at the NASA Classroom of the Future ${ }^{\mathrm{TM}}$, the research and development organization of NASA, located at the Center for Educational Technologies at Wheeling Jesuit University. In the Observatory Site Selection investigation, students used light pollution data to select an observatory site. They also had access to atmospheric seeing and stability data at various potential sites. This type of investigation formed the basis of a number of other later programs at NOAO for teaching about illumination engineering and light pollution.

The pedagogical design of the Astronomy Village ${ }^{\circledR}$ investigations is based on research in interactive science laboratory instruction ${ }^{16}$ where students participate vigorously with a research investigation and as part of a experimental research team. The student participates in the many aspects of research and problem solving in ways that are nearly identical to how scientists conduct research. This approach has many advantages: 
- The investigations aid students' development of inquiry skills and give them an appreciation of the scientific enterprise and the interplay between technology and science.

- The investigative approach promotes the development of cognitive skills such as problem solving analysis, generalizing, critical thinking, applying, synthesizing, evaluating, and decision-making.

- Investigational, organizational, and communicative skills are developed and used regularly.

- Investigations provide a concrete experience and opportunity to confront student misconceptions (or alternative conceptions, as the case may be).

- The data manipulation and analysis activities provide an understanding of the continuity of the scientific process.

- The hands-on activities and opportunities for manipulation of physical objects are valuable for students with kinesthetic learning styles.

- The cooperative learning environment promotes an examination of the data from different perspectives and provides strong motivation for students to stay on task.

- The investigational environment provides ample opportunity for building and communicating values concerning the nature of science.

Figure 1: The Astronomy Village environment provides an immersive investigational environment with access to varied data. The exploratory nature of science is reinforced through the use of many locations where experiments are designed, conducted, evaluated, and discussed. Most of the work is done in

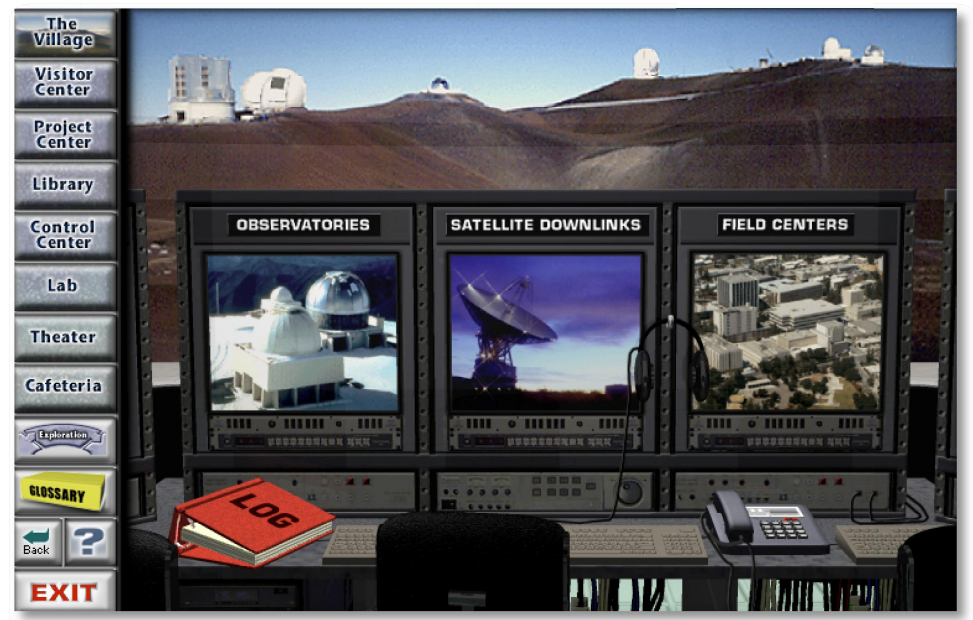
collaborative groups.

The program uses problem-based learning and ill-structured problems and showed the value of such a program to teach problem-solving skills, ${ }^{17}$ which we have applied in the following projects.

\section{B. Exploring the Environment}

Exploring the Environment ${ }^{\mathrm{TM}}$ was another educational product from the NASA Classroom of the Future ${ }^{\mathrm{TM}}$ using a problem-based learning approach to have students use NASA remote sensing images to address environmental problems. ${ }^{18}$ The Exploring the Environment ${ }^{\mathrm{TM}}$ project created a series of interdisciplinary, problem-based learning (PBL) modules for high school students. The project had many unique characteristics. It motivated student teams to address real-world problems using NASA remote sensing data. The problems that were addressed were varied, and included problems related to biodiversity, weather, land use, volcanoes, and global warming.

Figure 2: Overview of the Exploring the Environment ${ }^{\mathrm{TM}}$ problems that utilize remote sensing data and problem-based learning.

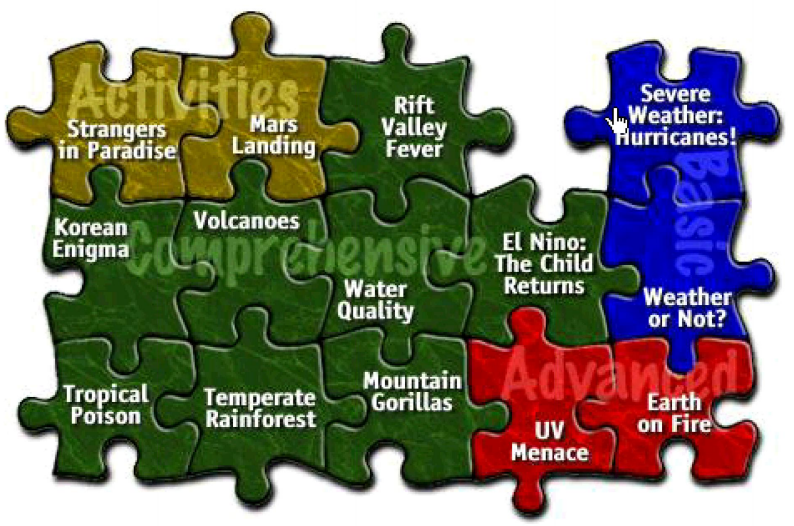


One problem-based learning module compared satellite images of North and South Korea in order to assess the amount of light generated in each country, a reflection of their economic and industrialization levels, as well as other factors. ${ }^{19}$ In addition to having students interpret remotely-sensed images of these two countries, the students also communicated their findings to other students at other schools. They could also communicate with scientists for answers to questions. The students and teachers were striving to create solutions to open-ended earth science problems using many of the same tools, such as image processing, and the same data (e.g. Landsat satellite images) as scientists. This authentic problem solving approach is highly conducive to improving the pedagogical content knowledge of teachers and in giving students a taste of authentic science.

This curricular product has a number of interesting attributes regarding the responsibilities of the student and the teacher. In this program, students have the additional responsibility of defining the problem being solved and learning to use the tools they need to solve it. In this instructional system the teacher is not the focal point of the classroom but serves as an instructional coach or a resource person. This helps the student in progressing from a "novice" approach to an "expert" approach to problem solving. Since there is no single right answer to the problem being solved, the evaluation of which answer is best or achieves the desired results rests on both the student and teacher and on the quality of the communication among the students and teacher.

\section{Hands-On Optics}

In the NSF-sponsored program "Hands-On Optics: Making a Difference with Light", six innovative modules were developed for middle school students that could be used in both formal and informal settings ${ }^{20}{ }^{20}$ The HOO modules were developed as a collaborative project among OSA, SPIE, and the National Optical Astronomy Observatory. As such there was input from academic optical scientists and engineers, practicing optical engineers, optics educators, teachers, and museum educators. This combination of talent led the project output to be named an exemplary project by the National Science Teachers Association. ${ }^{21}$ The Hands-On Optics (HOO) modules stressed in-depth investigations and provided all

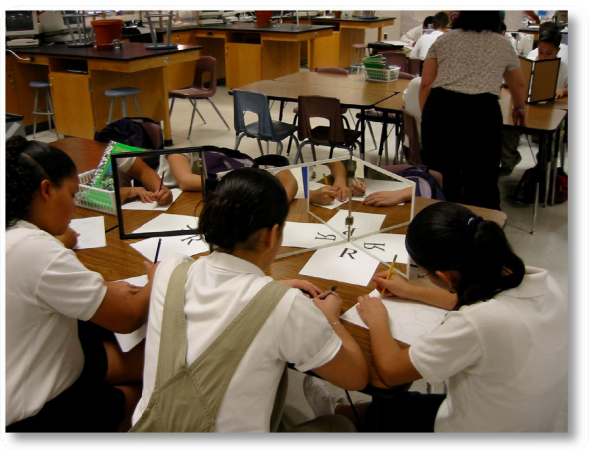
of the experimental materials necessary for deep investigations. Several features made these materials educative. The materials came with an extensive teachers guide that was in the pedagogical style of the wellregarded Great Explorations in Math and Science (GEMS) teacher guides developed by the University of California Berkeley's Lawrence Hall of Science. ${ }^{22}$ The $\mathrm{HOO}$ teacher guides contained an extensive discussion of student misconceptions and naïve theories that were relevant to each investigation. Each investigation also culminated in a design challenge which was also a form of authentic assessment. The HOO modules dealt with fundamental aspects of light relevant to illumination engineering, such as multiple reflections, polarization, and the electromagnetic spectrum. The students also worked in small groups, much like scientific teams.

Figure 3: Students working on multiple reflections in Hands-On Optics Module 2.

\section{Globe at Night}

Light pollution is a significant concern for the astronomical research enterprise. ${ }^{23} \mathrm{NOAO}$ has been an international leader in creating educational programs in illumination engineering centered on this topic. ${ }^{24}$ Our local education efforts expanded when we created a citizen science program called Globe at Night, where citizen could record and post measurements of their local night sky brightness. ${ }^{25,}{ }^{26}$ These efforts grew and evolved significantly during the International Year of Astronomy $2009 .{ }^{27,} 28$

Figure 4: The NOAO Globe at Night program conducts worldwide assessments of the night sky using citizen

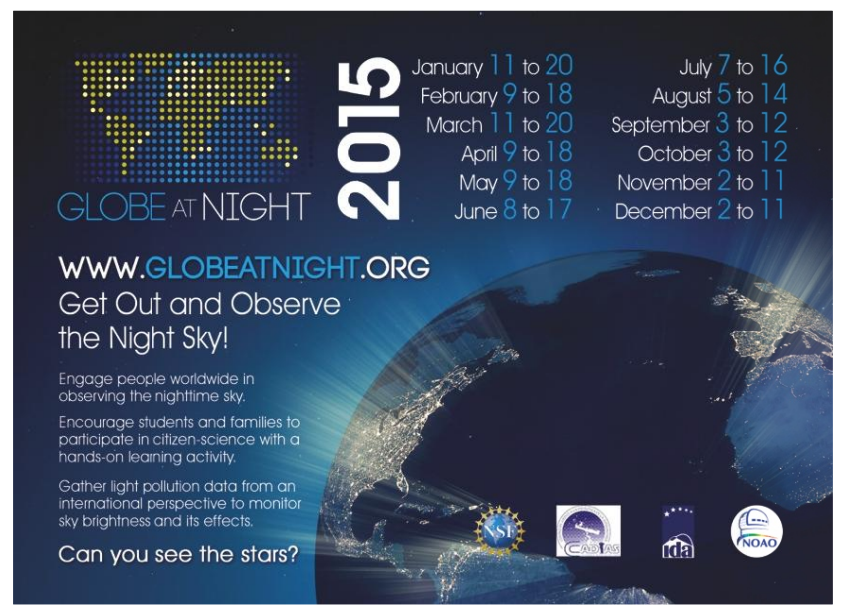
scientists, who make visual observations, Sky Quality Meter measurements, and measurements made with cell phone applications to assess the night sky brightness. 
The Globe at Night program is an international citizen-science campaign to raise public awareness of the impact of light pollution. It works by inviting citizen-scientists to measure their night sky brightness and submit their observations using a computer or smart phone. More than 164,000 measurements have been contributed from people in 180 countries during the campaigns which have run each winter and spring over the last 11 years, making Globe at Night the most successful light pollution awareness campaign to date. The data in our interactive map can be explored as well, and used for student-generated research projects. The database is usable for comparisons with a variety of other databases and geographic information systems. Using this combination allows research projects such as how light pollution affects the movement and foraging habits of nocturnal animals such as bats.

\section{E. Quality Lighting Teaching Kit}

A specialized yearlong program for the International Year of Astronomy 2009 incorporated many different programs related to optics education and dark skies education. ${ }^{29,} 30,31$ As part of this effort, several kits and programs were developed at NOAO including the Dark Skies Awareness kit and the Dark Skies Rangers programs. The Dark Skies Awareness kit included a wide variety of activities to teach basic principles of lighting and the effect of light on animals. ${ }^{32}$ It also included an outdoor lighting audit activity, where students made assessments of lighting in their neighborhoods or in the school building and school surroundings. More than 500 of these teaching kits have been distributed. High quality professional development was given to many of the teachers who received kits.

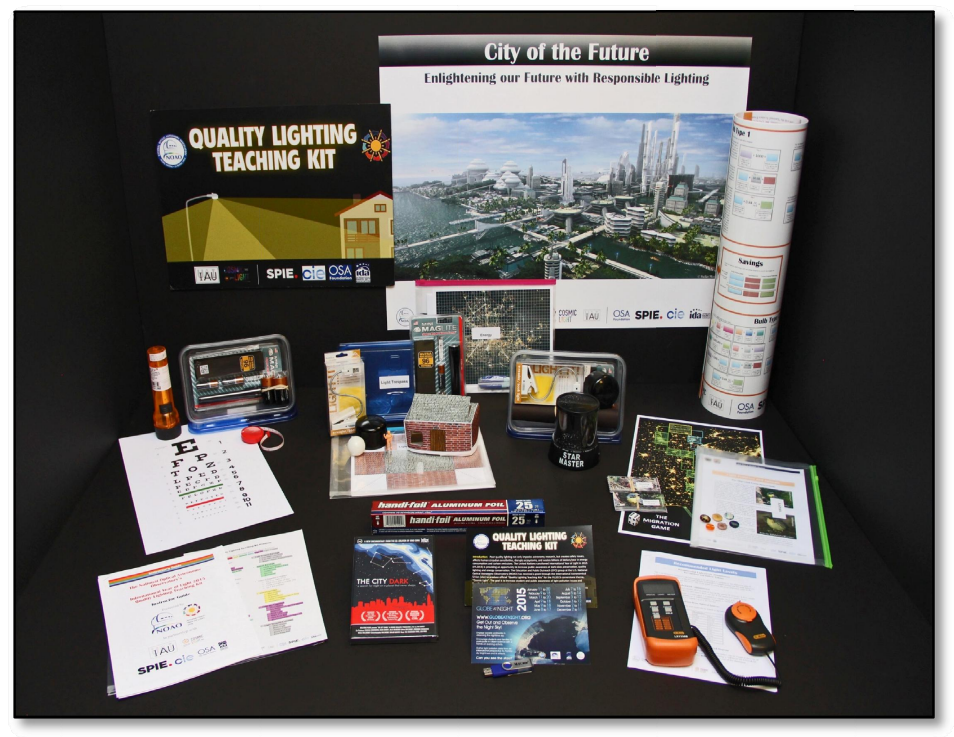

Figure 5: The NOAO Quality Lighting Teaching Kits have been distributed worldwide to allow students to start solving illuminating engineering issues connected with outdoor lighting.

To create more educative curricular materials, NOAO designed a problem-based learning kit for the International Year of Light 2015. ${ }^{33,34}$ Incorporating many of the principles used in the NOAO kits and in the Photon II program, NOAO shifted the focus from an activity-based program, a standard in many classrooms, to a problem-based learning program. This program represents our latest effort to strongly engage students in authentic problem-solving. The program was based on the lessons we learned from successful programs with diverse audiences, including our Dark Skies Africa ${ }^{35}$ and Dark Skies Yuma programs. ${ }^{36}$

In the new program, the teacher plays the role of a town's mayor and the students are researchers advising the mayor. The student problem-solving efforts center around a series of complaints registered by citizens to the mayor's office. The students must now address and try to solve these problems. In this approach, the Quality Lighting Teaching Kit builds on our philosophy and previous work in our design of programs to teach illumination engineering. ${ }^{37}$ The program uses a team approach that address real world problems using authentic tools, such as a lux meter. The problems that the students address fall into 6 categories: Glare and the Aging Eye, Light Trespass, Wildlife, Energy, Sky Glow, and Safety.

\section{F. Colors of Nature Program}

NOAO is a partner in the program "Project STEAM: Integrating Art with Science to Build Science Identities among Girls" or "Colors of Nature". The project is funded by the National Science Foundation, under the aegis of the program on Advancing Informal STEM Learning (AISL). The general rationale for this program has been addressed previously. ${ }^{38}$ The program addresses illumination engineering through a strong emphasis on light sources, the reflective properties of materials, and the detective attributes of animal eyes and cameras. The program also uses an Ocean Optics spectrometer that students use to measure the spectral characteristics of different materials. The program does not use problem-based 
learning quite in the ways described earlier in this paper, but rather is oriented towards design challenges. With design challenges students have broad latitude to create art-science based creative solutions. This program serves a younger audience: generally girls aged $10-12$ years old.

A key and novel part of the program focuses on creating a science identity in the girls participating in the program. ${ }^{39}$ Embedded in the program is a strong pedagogical framework on the value of experimentation and the importance of positive self-talk when designing and creating. This emphasis on creating an approving atmosphere for the students as they create is a key area that is of increasing importance in the design of science education programs. This is particularly important when students are in a school environment that emphasizes conformity and "getting the right answer". We encourage novel approaches to design challenges using optics that do not have a "right" or "best" answer. In this sense, the program has similarities to problem-based learning. However, in this program, we do not place as much emphasis on finding optimal solutions or in evaluating multiple solutions. Rather, we appreciate the diversity of design solutions.

In our instructor training for this program, we emphasize that there is no right answer and that students should not criticize the work of others or of themselves during the design process, but rather enjoy the creative process until the project or design is completed. The instructional materials also reflect this level of openness and support.

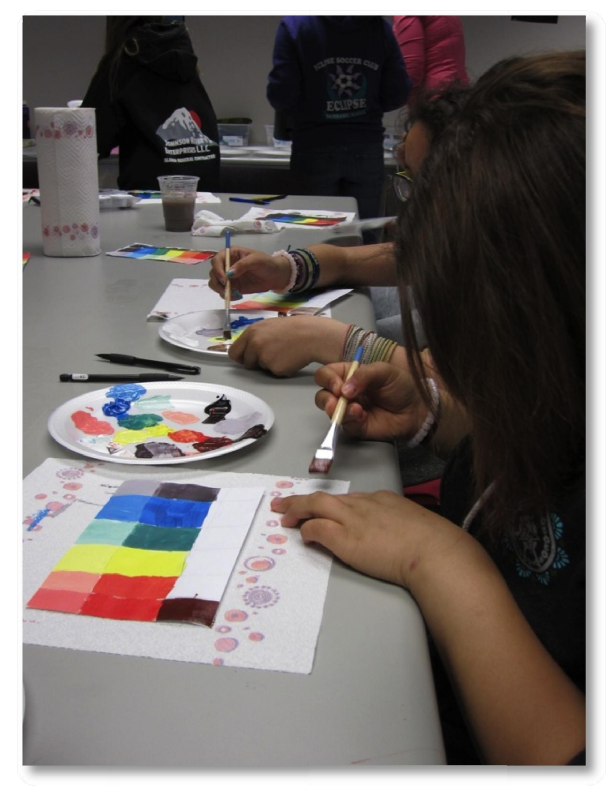

Figure 6: Students explore colors using art techniques and science tools such as spectrometers as they create responses to design challenges.

\section{TEAM APPROACHES TO CREATING HIGH QUALITY EDUCATIVE MATERIALS}

For over a decade, NOAO has been using a team-based approach to create instructional materials and programs that address optics and photonics education in ways that are congruent with the education mission in the charter of the U.S. National Science Foundation (NOAO's funder) and with NSF's strategic goals. ${ }^{40,}{ }^{41}$ Some programs are based in Arizona. ${ }^{42}$ Others are national in scope, as when NOAO and its partners SPIE and OSA used a team to create informal science education optics kits as part of the Hands-On Optics project. ${ }^{43,44}$ They also build on our more recent efforts such as the Galileoscope project where over 200,000 Galileoscope telescope kits that we developed with an international team have been distributed worldwide. ${ }^{45}$

Science-rich research institutions such as the National Optical Astronomy Observatory are well positioned to play a role in developing educative curriculum materials that enhance the pedagogical content knowledge of educators. This is because NOAO has uniquely qualified people with combined science and science education backgrounds who can contribute to the development process and infuse the materials with a high level of authenticity. They can also review materials for their approach and scientific accuracy. A key attribute is our ability to make judgments about approaches or areas of emphasis in the design of the curricular or instructional materials. Research institutions like NOAO also work with a cadre of postdoctoral, undergraduate, and graduate science students, and collaborate with nearby universities such as the University of Arizona on educational projects. ${ }^{46}$ These collaborations also can also help K-12 students in the community to understand and identify with the science process and to begin to form a science identity. ${ }^{47}$

To achieve these benefits, our instructional design team has members with experience as scientists and engineers and as educators in schools and museums. We do not believe that there should be any disconnect between pedagogical experts and content experts in the development process or that each aspect should be developed separately or sequentially. Our staff members have experience in both realms, so there is no sharp boundary between expertise in content and pedagogy. The domains are closely connected in our team approach. Some other skills of our team are: 
- Experience with U.S. national science education standards (e.g., "Next Generation Science Standards"48) in mathematics, technology, and science education.

- High level of specialized content knowledge and specialized pedagogical experience in teaching the topic

- Experience in teaching diverse students, including Native American and Hispanic students, which leads to an understanding of cross-cultural factors that influence professional development. ${ }^{49}$

- Experience with both in school and out of school settings

- Experience with game- and simulation-based approaches

- Experience with authentic tools (e.g. measurement tools)

- Experience with best practices in educator professional development design and delivery ${ }^{50}$

- Experience with optics misconceptions research ${ }^{51,52}$ and the assessment of a student's conceptual knowledge of optics using formative assessment probes ${ }^{53}$

- An appreciation of the value of collaboration between formal and informal institutions ${ }^{54}$

These team-based skills allow us to continue to develop high quality educator curriculum materials and to enhance the PCK of educators.

\section{CONCLUSION}

The development of Pedagogical Content Knowledge is critical for the science educator. To support this development, NOAO has created educative curriculum materials in the area of illumination engineering education. We have created instructional materials that incorporate best practices using problem-based learning and other innovative approaches to establish a more authentic and supportive learning environment. This approach has proven successful since it requires students to develop critical thinking and communication skills that can be applied in the work force. It also teaches them how to positively and constructively approach complex problems and to create the appropriate framework for problem solving. These efforts are part of the larger effort at the National Optical Astronomy Observatory to create high quality instructional programs and materials for dark sky preservation and energy conservation. We hope that our efforts also provide a solid foundation for progressive illumination engineering education at the pre-college level.

\section{Acknowledgements}

The National Optical Astronomy Observatory is operated by the Association of Universities for Research in Astronomy (AURA), Inc. under a cooperative agreement with the National Science Foundation. Any opinions, findings, and conclusions or recommendations expressed in this material are those of the authors and do not necessarily reflect the views of the National Science Foundation. "Project STEAM: Integrating Art with Science to Build Science Identities among Girls" is supported by the National Science Foundation under AISL Grant Number DRL-1224020. The Quality Lighting Teaching kits and the Dark Skies Africa program were supported, in part, by a grant from the International Astronomical Union. Dark Skies Yuma was supported in part by a grant from the APS Foundation. The Astronomy Village $^{\circledR}$ : Investigating the Universe ${ }^{\mathrm{TM}}$ project was supported by NASA. The Astronomy Village ${ }^{\circledR}$ : Investigating the Solar System ${ }^{\mathrm{TM}}$ project and Globe at Night were supported by the National Science Foundation.

\section{REFERENCES}

\footnotetext{
[1] Donnelly, J., Dischino, M., Hanes, F., Masa, N., “Creating and Using Industry-Based Problem-Based Learning Challenges in Photonics: Lessons Learned,” Proc. of SPIE Vol. 966611-2 (2009). [2] Massa, N. M., Dischino, M., Donnelly, J. F. \& Hanes, F.D, “Problem-Based Learning in Photonics Education: Assessing Student Learning,” ETOP Proceedings (2009).

[3] Pompea, S. M., Walker, C, and Sparks, R., "The Evolution of Optics Education at the U.S. National Optical Astronomy Observatory," Proc. SPIE 9289, 12th Education and Training in Optics and Photonics Conference, 92890 U (July 17, 2014).

[4] Shulman, L. S., "Those who understand: Knowledge growth in teaching," Educational Researcher, 15(2), 4- 31 (1986).

[5] Van Driel, J. H., \& Berry, A., "The teacher education knowledge base: Pedagogical content knowledge,” In P. L. Peterson, E. Baker, \& B. McGaw (Eds.), [Third international encyclopedia of education] Vol. 7, pp. 656-661. Amsterdam, The Netherlands: Elsevier (2010).

[6] Abell, S. K., "Research on science teacher knowledge," In S. Abell \& N. Lederman (Eds.), [Handbook of research on science education] pp. 1105-1149 Mahwah, NJ: Lawrence Erlbaum (2007).
} 
[7] Hashweh, M., "Teacher pedagogical constructions: A reconfiguration of pedagogical content knowledge," [Teachers and Teaching: Theory and Practice], 11, 273-292 (2005).

[8] Davis, E.A., and Krajcik, J.S., "Designing educative curriculum materials to promote teacher learning," Educational researcher 34, no. 3: 3-14 (2005).

[9] Singer, J., Marx, R.W., Krajcik, J., and Chambers, J.C., "Constructing extended inquiry projects: Curriculum materials for science education reform," Educational Psychologist 35, no. 3, 165-178. (2000)

[10] Davis, E., Annemarie Sullivan Palincsar, A.S., Arias, A.M., Bismack, A.S., Marulis, L., and Iwashyna, S., "Designing educative curriculum materials: A theoretically and empirically driven process," Harvard Educational Review 84, no. 1, 24-52. (2014).

[11] Hall-Wallace, M., Regens, N. L., and Pompea, S. M., "Design of a Professional Development and Support Program for Future Photonics Industry Team Leaders," Proc. SPIE, 4588 (2002).

[12] Pompea, S. M., \& Blurton, C., "A walk through the Astronomy Village,” Mercury, 24, 32, (1995).

[13] Pompea, S. M. "The Astronomy Village," In [Astronomy Education: Current Developments, Future Coordination], vol. 89 , p. 259 (1996).

[14] Pompea, S. M., and C. Blurton. “The Astronomy Village: Investigating the Universe,” In [New Trends in Astronomy Teaching (IAU Colloquium 162)], Cambridge University Press, pp. 332-337. (1998).

[15] Croft, S. K., and S. M. Pompea. "Astronomy Village: Experiencing the Process of Science in a Multimedia Environment," In 37th Annual Lunar and Planetary Science Conference, vol. 37. (2006). [16] Lazarowitz, R. and Tamir, P., "Research on using laboratory instruction in science," In [Handbook of research on science teaching and learning], 94-130 (1994).

[17] Hong, N. S., McGee, S. and Howard, B. C., "The Effect of Multimedia Learning Environments on Well-Structured and Ill-Structured Problem-Solving Skills," (2000).

[18 Myers, R. J., James A. Botti, J., and Pompea, S. M., "Design, development, and implementation of an inquiry-based, technology-rich, science curriculum," ERIC Clearinghouse (1997).

[19 Narisada, K., and Schreuder, D., [Light Pollution Handbook] Vol. 322. Springer Science \& Business Media (2004).

[20] Pompea, S. M., Johnson, A., Arthurs, E., \& Walker, C. E., "Hands-On Optics: An Educational Initiative for Exploring Light and Color in After-School Programs, Museums, and Hands-On Science Centers," In Proceedings, Ninth International Topical Meeting on Education and Training in Optics and Photonics, Marseille, France (2005).

[21] Pompea, S. M., Walker, C. E., \& Sparks, R. T., Knowledge and Wonder: Engagements with Light and Color in the Hands-On Optics Project," [Exemplary Science in Informal Education Settings: Standards-Based Success Stories], edited by R. Yager and J. Falk, 47-70 (2008).

[22] Pompea, S. M., Gould, A. and Bergman, L. [Invisible Universe: The Electromagnetic Spectrum from Radio Waves to Gamma Rays] Great Explorations in Math and Science (GEMS), University of California Berkeley (2002).

[23 Luginbuhl, C. B., Walker, C. E., and Wainscoat, R. J., "Lighting and astronomy," Physics Today 62, no. 12 32-37 (2009).

[24] Walker, C. E., Pompea, S. M., Sparks, R. T., and Dokter, E., "Teaching illumination engineering using light pollution education kits," In SPIE Optical Engineering+ Applications, pp. 77830H77830H. International Society for Optics and Photonics (2010).

[25] Walker, C. E., S. M. Pompea, and R. T. Sparks. "Dark Skies From the Ground Up: Before, During and After GLOBE at Night," [Earth and Space Science: Making Connections in Education and Public Outreach], vol. 443, p. 345 (2011).

[26] Kyba, C., Wagner, J. M., Kuechly, H. U., Walker, C. E., Elvidge, C. D., Falchi, F., Ruhtz, T., Fischer, J., and Hölker, F., "Citizen science provides valuable data for monitoring global night sky luminance," Scientific reports 3, 1835. (2013).

[27] Walker, C. E., Pompea, S. M., and Isbell, D., "GLOBE at Night 2.0: on the Road Toward IYA2009," in [Education and Public Outreach - A Changing World: Creating Linkages and Expanding Partnerships], Astronomical Society of the Pacific Conference Series 389, eds. C. Garmany, M.G. Gibbs, J.W. Moody (2008).

[28] Barringer, D., Walker, C.E., Pompea, S.M., and Sparks, R.T., “Astronomy Meets the Environmental Sciences: Using GLOBE at Night Data,” In [Earth and Space Science: Making Connections in Education and Public Outreach], vol. 443, p. 373 (2011).

[29] Walker, C. E., Berglund, K., Bueter, C., Gauthier, A., Gay, P.L., Foster, T., Patten, K., Pompea, S.M., Sparks, R., and Smith, C., "Dark Skies from the Ground Up: Part 1. Resources to Raise Awareness During the International Year of Astronomy," [Preparing for the 2009 International Year of Astronomy: A Hands-On Symposium] vol. 400, p. 110 (2008).

[30] Walker, C. E., Sparks, R. T., and. Pompea, S. M, "Optics Education in the International Year of Astronomy," in Proceedings Education and Training in Optics and Photonics (2007).

[31] Pompea, S. M., Schweitzer, A., Deustua, S., Isbell, D., Fienberg, R. T., Arion, D. N., Walker, C. E., et al. "International Year of Astronomy 2009 Cornerstone Projects: What's Available for You," [Science Education and Outreach: Forging a Path to the Future], vol. 431, p. 86 (2010).

[32] Walker, C. E., Pompea, S. M., Sparks, R. T., and Dokter, E., “Teaching illumination engineering using light pollution education kits,” In SPIE Optical Engineering+ Applications, pp. 77830H$77830 \mathrm{H}$. International Society for Optics and Photonics (2010).

[33]https://www.iau.org/iyl/cornerstones/cosmiclightawareness/

[34] Walker, C. E., and Pompea, S. M., “The Quality Lighting Teaching Kit: enlightening our future,” In SPIE Optical Engineering+ Applications, pp. 99460Q-99460Q. International Society for Optics and Photonics (2016).

[35] Walker, C. E., Tellez, D., and Pompea, S. M., "Dark Skies Africa," Proceedings of the International Astronomical Union 11, no. A29A, 408-409 (2015).

[36] Pompea, S. M., Walker, C. E., Dugan, C., Roddy, W. T., and Newhouse, M. "Dark Skies Yuma: An NOAO and APS Program on Light Pollution Education,” In American Astronomical Society Meeting Abstracts, vol. 223 (2014).

[37] Walker, C. E. and Pompea, S. M. ,"National Education Program for Energy Efficient Illumination Engineering," Proceedings SPIE: Eco-Photonics 2011: Sustainable Design, Manufacturing, and Engineering Workforce Education for a Green Future, March 29, 2011, Strasbourg, France (2011).

[38] Pompea, S. M., and Carsten-Conner, L. D., "Teaching Optics Concepts through an Approach that Emphasizes the "Colors of Nature," in Education and Training in Optics and Photonics, p. OUT01. Optical Society of America (2015).

[39] Tzou, C., Conner, L., Guthrie, M., and Pompea, S., “Colors of Nature: connecting science and arts education to promote STEM-related identity work in middle school girls," In Polman, J. L., Kyza, E., O’Neill, D. K., Tabak, I., Penuel, W. R., Jurow, A. S., O’Connor, K., Lee, T., and D’Amico, L. (Eds.). Proceedings of the International Conference of the Learning Sciences (ICLS) 2014: Learning and becoming in practice 3:1555-1556 (2014).

[40] The National Science Foundation Act of 1950 (Public Law 81-507).

[41 ] "Empowering the Nation through Discovery and Innovation", NSF Strategic Plan for Fiscal Years 2011-2016.

[42] Pompea, S. M., Fine, L. W., and Meystre, P., "Photonics Education for a Green Future: Connecting the Dots of the Arizona STEM Education Experiment," Proceedings SPIE: Eco-Photonics 2011: Sustainable Design, Manufacturing, and Engineering Workforce Education for a Green Future, March 29, 2011, Strasbourg, France (2011).

[43] Pompea, S. M., Walker, C. E., and Sparks, R. T. "Knowledge and Wonder: Engagements with Light and Color in the Hands-On Optics Project," in [Exemplary Science in Informal Education Settings: Standards-Based Success Stories], edited by R. Yager and J. Falk, 47-70, NSTA Press (2008). 
[44] Pompea, S. M., Johnson, A., Arthurs E. and Walker, C. E, "Hands-On Optics: An Educational Initiative for Exploring Light and Color in After-School Programs, Museums, and Hands-On Science Centers", Proc. Ninth International Topical Meeting on Education and Training in Optics and Photonics, Marseille, France (2005).

[45] Pompea, S. M., Fienberg, R., Deustua, S., and Isbell, D., "Telescope Kits \& Optics Challenges for the International Year of Astronomy 2009," [Education and Public Outreach - A Changing World: Creating Linkages and Expanding Partnerships], Astronomical Society of the Pacific Conference Series 389, eds. C. Garmany, M.G. Gibbs, J.W. Moody (2008).

[46] Hall-Wallace, M., Regens, N.L., and Pompea, S.M., "University of Arizona's Collaboration to Advance Teaching Technology and Science (CATTS): Lesson for Photonics Education Collaborations," Proceedings of the SPIE: Education and Training in Optics and Photonics, 4588 (2002).

[47] Tzou, C., Conner, L., Guthrie, M., and Pompea, S., "Colors of Nature: connecting science and arts education to promote STEM-related identity work in middle school girls," In Polman, J. L., Kyza, E., O'Neill, D. K., Tabak, I., Penuel, W. R., Jurow, A. S., O'Connor, K., Lee, T., and D'Amico, L. (Eds.). Proceedings of the International Conference of the Learning Sciences (ICLS) 2014: Learning and becoming in practice 3:1555-1556 (2014).

[48] Achieve, Inc. on behalf of the twenty-six states and partners that collaborated on the NGSS, "Next Generation Science Standards for Engineering, Technology, and the Applications of Science", Next Generation Science Standards, Achieve, Inc. (2013)

[49] Hall-Wallace, M., Regens, N. L., and Pompea, S. M., "Design of a Professional Development and Support Program for Future Photonics Industry Team Leaders," Proc. SPIE, 4588 (2002). [50] Loucks-Horsley, S., Stiles, K. E., Mundry, S., \& Hewson, P. W. (Eds.). [Designing professional development for teachers of science and mathematics] Corwin Press (2009).

[51] Pompea, S. M., Dokter, E. F., Walker, C. E., and Sparks, R. T., "Using Misconceptions Research in the Design of Optics Instructional Materials and Teacher Professional Development Programs," Proceedings Education and Training in Optics and Photonics 2007, Ottawa, Canada, (2007).

[52] Driver, R., Squires, A., Rushworth, P., and Wood-Robinson, V., [Making Sense of Secondary Science: Research Into Children's Ideas], Ch. 17: Light, London: Routledge (1994).

[53] Dokter, E. F. C. , Pompea, S. M. , Sparks, R. T. , Walker, C. E. , "The Development of Formative Assessment Probes for Optics Education," Proceedings SPIE: Optics Education and Outreach, Vol 7783 (2010).

[54] Bevan, B. with Dillon, J., Hein, G.E., Macdonald, M., Michalchik, V., Miller, D., Root, D., Rudder, L., Xanthoudaki, M., \& Yoon, S., "Making Science Matter: Collaborations Between Informal Science Education Organizations and Schools. A CAISE Inquiry Group Report,” Washington, D.C.: Center for Advancement of Informal Science Education (CAISE) (2010). 